UDK 781.97

Darja Frelih

Znanstvenoraziskovalni center SAZU, Ljubljana

Scientific Research Centre at the Slovenian Academy of Sciences and Arts, Ljubljana

\title{
Katalogiziranje glasbenih virov za RISM v Sloveniji*
}

\section{Cataloguing for RISM in Slovenia}

Ključne besede: muzikologija, katalogi, glasbeni rokopisi, slovenska glasba

\section{PovzeTeK}

Slovenija sodeluje $\mathrm{v}$ mednarodnem projektu RISM (Répertoire International des Sources $\mathrm{Mu}$ sicales = International Inventory of Musical Sources), pri Seriji A/II (Music Manuscripts after 1600) od leta 1993. Tedaj so na Muzikološkem inštitutu ZRC SAZU (Institute of Musicology at Scientific Research Centre of the Slovenian Academy of Sciences \& Arts) v Ljubljani pričeli popisovati starejše glasbene rokopise $z$ območja Slovenije s pomočjo računalniškega programa PIKaDo in začeli sodelovati s centralno redakcijo RISM v Frankfurtu na Maini. Rezultati tega dela izidejo vsako leto (skupaj s podatki iz okoli 30 centrov po drugih državah) v obliki tematskega kataloga na CD-ROMU. Ta bo sčasoma nadomestil "stari" klasični listkovni katalog na Muzikološkem inštitutu, ki trenutno hrani popise za okrog 1300 enot glasbenega rokopisnega gradiva, ki so jih sodelavci inštituta zbrali doslej (a v njem še ni zajeto gradivo iz vseh nahajališč).

$\mathrm{V}$ primerjavi s klasičnim katalogiziranjem računalniško terja od popisovalca natančnejše podatke o rokopisu (med drugim opis vodnih znamenj na papirju) in popis večjega števila glasbenih incipitov (saj program v centralni redakciji avto-
Keywords: musicology, catalogues, musical manuscripts, Slovene music

SuMMARY

Since 1993 Slovenia has been taking an active part in the international project of RISM (Répertoire International des Sources Musicales - International Inventory of Musical Sources), with the Series A/II (Music Manuscripts after 1600). In that year the RISM national group for Slovenia was founded in the Institute of Musicology at ZRC SAZU in Ljubljana and the PIKaDo computer programme installed, by the aid of which the cooperation with the Central editorial offices in Frankfurt am Main, Germany, proceded. The results are issued every year on a RISM CD-ROM in the form of a thematic catalogue of old music manuscripts from all over the world (data from about 30 countries). Gradually it will replace our conventional card catalogue that now contains about 1300 units of musical manuscript material, collected in the past years by Institute collaborators in various Slovene archives. The completion of this work is being carried out by incorporation into RISM.

To ensure utmost precision of the RISM-cataloguing the Institute professionals borrow the original manuscripts from Slovene musical archives (three up to now). Such a metod offers also an

\footnotetext{
* Verzija referata $\mathrm{v}$ angleščini je bila predstavljena na kongresu "Wissenschaftliche und technische Herausforderung der musikhistorischen Quellenforschung im internationalen Rahmen”, ki je potekal od 6. do 9. marca 2002 v Frankfurtu na Maini ob 50-letnici RISM-a.
} 
matsko primerja podatke in ima možnost in "sposobnost dešifriranja" avtorjev, ki veljajo za anonimne. Z namenom, da bi ustregli tem zahtevam, so si na inštitutu izposodili gradivo (doslej iz treh arhivov), ki ga na novo katalogizirajo, obenem pa še skenirajo. Tako bodo dodatno poskrbeli še za hrambo gradiva na sekundarni lokaciji in za ustrezno dostopnost le-tega za nadaljnje muzikološke raziskave.

V letih 1993-1998 je bilo opravljenih 306 računalniških vnosov, v zadnjih štirih letih, odkar je posebej za ta namen zaposlena ena sodelavka, pa dodatnih 666. Avtorica se v prispevku osredotoča na nekatere vidike katalogiziranja, zlasti na vprašanje $\mathrm{v}$ zvezi $\mathrm{z}$ navajanjem zasedbe (kategoriji "Scoring" in "Scoring block") oziroma dejanskega stanja gradiva, na vprašanje možnih izmenjav podatkov med katalogizatorji, kadar gre za rokopise manj znanih avtorjev ter na vprašanja "timinga" oziroma bolj učinkovite izrabe časa, namenjenega katalogiziranju za RISM. opportunity to scan this temporarily available material. Musical manuscripts are thus preserved at a second location and available for further musicological research. Since 1998 full time post for the RISM-cataloguing work has been established at the Institute. Till then, 306 computer records had been made and in the last years further 666 . The author of this article concentrates on some aspects of cataloguing for RISM, e.g. on quotations in the categories of scoring, scoring block and statement of material, on research possibilites of information exchange about less known manuscript composers, and on the timing and/ or efficiency improvement of the work involving the RISM project.

Slovenija je ena izmed več kot 30 držav, ki se vključujejo v mednarodni projekt RISM (Répertoire International des Sources Musicales). K sodelovanju v Seriji A/II, ki je namenjena katalogiziranju glasbenih rokopisov po letu 1600 (do 1850), smo pri nas pristopili leta 1993. Tedaj so na Muzikološkem inštitutu ZRC SAZU ustanovili nacionalni komite za RISM v Sloveniji in v povezavi s Centalno redakcijo RISM v Frankfurtu na Maini začeli s popisovanjem glasbenih virov v računalniškem programu PIKaDo (Pflege und Informationsverarbeitung kategorisierter Dokumente).

Sodelavci inštituta so na začetku računalniškega popisovanja vnašali v program podatke o rokopisih iz klasičnega, listkovnega kataloga, ki ga hrani Muzikološki inštitut. Ta "stari" katalog, ki je nastajal postopoma, vsebuje informacije za okoli 1.300 glasbenih rokopisov iz sedmih že obdelanih arhivov oziroma hranišč po Sloveniji, in je še vedno v rabi. ${ }^{1}$ Toda računalniško katalogiziranje $v$ primerjavi s prej omenjenim zahteva od popisovalca vnos veliko večjega števila podatkov in podrobnosti o posameznem rokopisu, na primer opise vodnih znamenj posameznih izdelovalcev papirja in med drugim tudi večje število glasbenih incipitov pri posamezni skladbi. ${ }^{2} \mathrm{Da}$ bi lahko zadostili zahtevam natančne obdelave gradiv, so se na inštitutu s posameznimi arhivi domenili za začasno izposodijo rokopisnega gradiva. Doslej pridobljeno gradivo iz arhivov ljubljanske Stolnice, Kapiteljskega arhiva iz Novega mesta in arhiva tamkajšnjega Frančiškanskega samostana (popis slednjega še poteka) ne bo le računalniško katalogizirano ampak tudi skenirano in tako še dodatno hranjeno za nadaljnje muzikološko raziskovanje in objave. $Z$ vključitvijo v omenjeni mednarodni projekt pri RISM smo tako pridobili smiselno izdelan računalniški program in obenem posodobili katalogiziranje nacionalne zbirke glasbenih rokopisov, ki tudi za vnaprej ostaja ena od permanentnih nalog Muzikološkega inštituta.

\footnotetext{
1 Sčasoma ga bodo nadomestili in pozneje vsebinsko tudi presegli rezultati računalniškega popisa po programu PIKaDo, ki vsako leto izidejo v obliki kumulativnega kataloga na CD-ROMU.

${ }^{2}$ Računalniški sitem $\mathrm{v}$ centralni redakciji avtomatsko medsebojno primerja vnešene notne zapise in pomaga odkrivati avtorje skladb, ki so v določenem arhivu dotlej veljali za anonimne.
} 


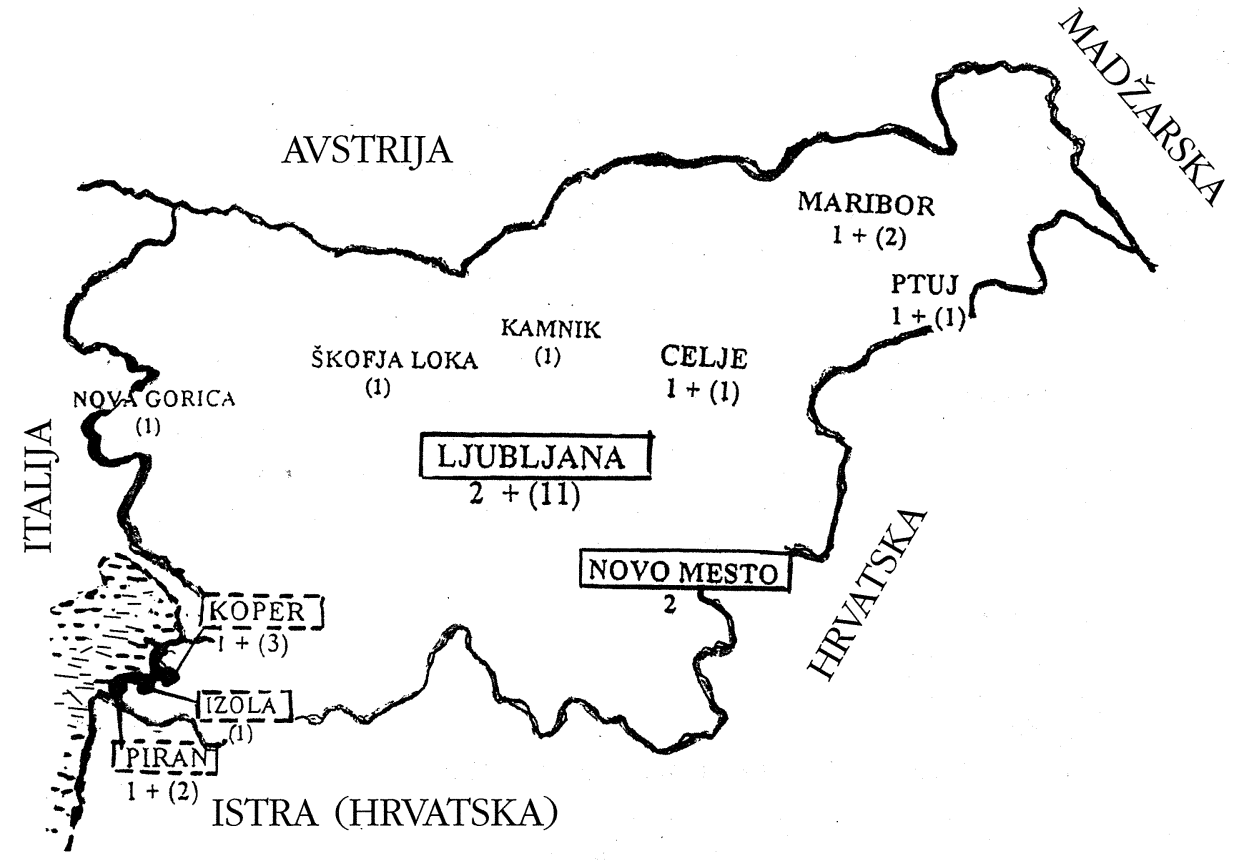

Primer 1: Nahajališča glasbenih rokopisov $v$ Sloveniji ${ }^{3}$

Do leta 1998 so posamezni raziskovalci $\mathrm{z}$ inštituta $\mathrm{v}$ program PIKaDo vnesli skupno 306 zapisov. Delo za RISM kot moja prednostna zadolžitev in zaposlitev se je začelo istega leta, po opravljenem tečaju katalogiziranja v Centralni redakciji v Frankfurtu. Do konca leta 2001 sem popisala še nadaljnjih 666 enot gradiva, kar je prikazano na spodnji tabeli.

\begin{tabular}{|l|c|c|c|c|c|}
\hline Nahajališča rokopisov & \multicolumn{5}{|l|}{ Število računalniško katalogiziranih enot v letih: } \\
\hline Sigla in ime arhiva & (do) $1998 \quad 1999$ & 2000 & 2001 & \multicolumn{1}{c|}{ Skupaj: } \\
\hline Ls - Ljubljanska stolnica & 181 & & & & \\
\hline Nf - Novo mesto, Frančiškanski samostan & $35+\mathbf{4 7}$ & $\mathbf{2 6 4}$ & $\mathbf{2 4 5}$ & $\mathbf{1 1 0}$ & $\mathbf{6 6 6}$ \\
\hline Nk - Novo mesto, Kapiteljski arhiv & 84 & & & & \\
\hline Ms - Mariborska stolnica & 4 & & & & \\
\hline Co - Celje, Opatijska cerkev Sv. Danijela & 1 & & & & \\
\hline Pk - Ptuj, Knjižnica Ivana Potrča & 1 & & & & \\
\hline Skupaj: & 306 & & & & 972 \\
\hline
\end{tabular}

Primer 2: Prikaz doslej popisanih glasbenih virov za RISM

\footnotetext{
${ }^{3} \mathrm{Za}$ podatke o nahajališčih prim.: "SI - Slovenia", v: RISM-Bibliothekssigel; Gesamtvrzeichnis. München, G. Henle in Kassel, Bärenreiter, 1999, str. 119-120.
} 
V prispevku bi se rada osredotočila na nekatera opažanja, posamezna vprašanja in predloge v zvezi s katalogiziranjem za RISM, ki je odvisno tako od strokovnih vedenj in tehničnih znanj, nič manj pa tudi iz privajanja nanj, kar pa je verjetno precej odvisno od posameznika. Šele ob delu s konkretnim gradivom prihaja do reševanja določenih vprašanj in poglabljanja znanja. Poučno je bilo na primer usklajevanje dveh kategorij, namenjenih popisu zasedbe in ugotovitev, da nista nujno povezani s kategorijo, ki prikazuje stanje gradiva. Pri vsaki skladbi, ki jo popisujemo, namreč v "blok zasedbe" (kat. 832) vnašamo podatke o njeni popolni vokalni in inštrumentalni zasedbi (vkolikor je ta znana iz diplomatskega naslova skladbe), v blok "zasedba" (kat. 160) pa samo njen skrajšani opis. Če zasedba ni znana, v prvo kategorijo vnesemo le oznako "no indication" (ni podatkov), drugo pa pustimo prazno. Ker pa se da o zasedbi sklepati tudi iz ohranjenega gradiva skladbe, lahko zaradi nezadostnega poznavanja pravil pride do vnašanja podatkov o glasovih v kategorijo zasedbe, kar pa ni pravilno. Ohranjene glasove smemo vpisati samo v kategorijo "stanje ohranjenega gradiva" (kat. 720 ) in jih ne smemo povezovati s prej omenjenima kategorijama za popis zasedbe.

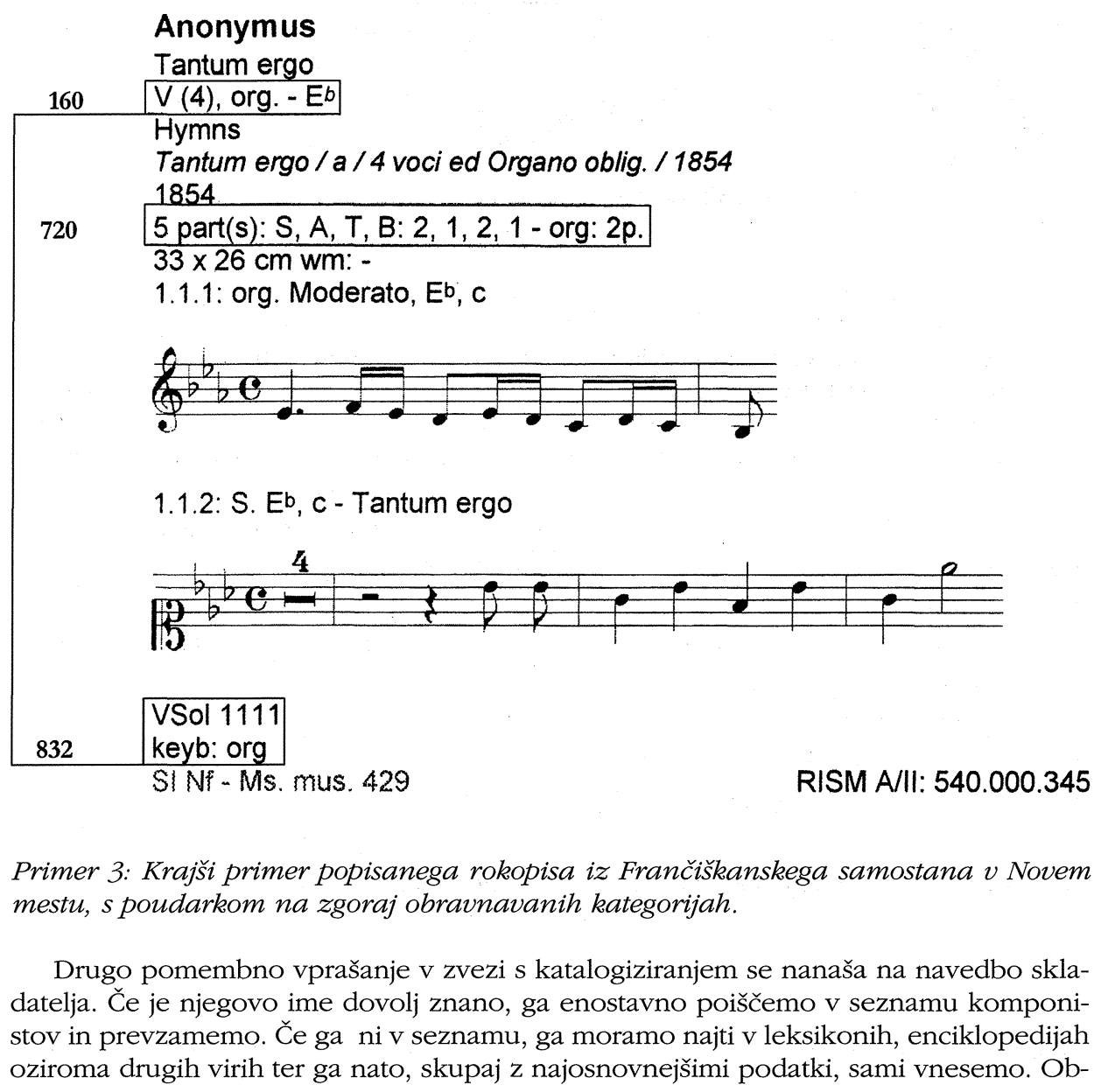


--Komponisten-

--23020 x Komponist 0 1.0--.

|--Nr.: 3660----Vollanzeige-

Komponist

weiblich

Wratny, Karl Wenzel :

$: 18 / 19$

: 0 RISM.A/I

: MGG

Rism-Zeit : unsicher :

: $0 \mathrm{MGG} / \mathrm{S}$

: 0 RIE

: GROVE

:0 N-GROVE |

: EITNER

: RIC/RIZ

: CS-LEX

others

:

$=$ RISM A/I

Wratny, Karl Wenzel $\quad$ (o. D.)

Suppan S 1 Wratny, (Karl) Wenzel (fl 1785-1789)

0 Mendel M 1

0 Frank T 19

0 Stieger 0

0 DEUMM

Comm nts: MGG: Siehe Artikel "Graz"

In HR Zha: Kompositionsdaten 1803-1808;

1796-1804 Mitglied der bischöflichen

Musikkapelle in Ljubljana

1.Entry 1995:xyz@abc.hr;

2.User 1997: SI, Ls: xyz@abc.si;

3. User 2000: SI, Nf: nn@abc.si letc.l

Primer 4: Podatki o K.W. Wratnyju, prevzeti iz seznama skladateljev v programu PIKaDo. (Podatki $v$ zadnjih treh vrsticah so izmišljeni in naknadno dodani kot primer oziroma predlog dopolnitve maske). 
staja tudi možnost, da o avtorju ne najdemo nobenih podatkov in poleg priimka in imena (brez navedbe letnic) vnesemo v seznam samo kratico dežele in nahajališča, v katerem hranijo rokopis. $\mathrm{V}$ takem primeru bi bilo zanimivo vedeti, kateri katalogizator je ime skladatelja prvi vnesel ter kdo in kje je te podatke pozneje prevzel. Zato predlagam, da bi takšno informacijo dodali v obstoječi seznam. Verjetno ne bi zavzela veliko prostora, za raziskovalca pa bi bila vsaka nadaljnja informacija o avtorju in ostalih nahajališčih njegovih rokopisov zelo dobrodošla.

Naj v zvezi s tem navedem primer: dóselj katalogizirano gradivo Frančiškanskega samostana iz Novega mesta obsega 60 zbirk, 262 del anonimnih avtorjev in 344 skladb 75 komponistov. Med slednjimi se pojavljajo imena, ki so slovenskemu muzikologu bolj ali manj zanana, na primer Kamilo in Gašper Mašek, Karl Wenzel Wratny, Leopold Schwerdt, Amando Ivančič oziroma imena skladateljev, povezanih z delovanjem v frančiškanskem redu kot npr. Innocenc Gnidovec, Rafael Illowsky, Rafael Klemenčič, Josef Mikš ali Johann Schreiber. Odgovor na vprašanje, če in v katerih knjižnicah in arhivih se še nahajajo skladbe določenega avtorja, bi lahko dobili s poizvedbami na CD-ROMu, a če bi imeli na razpolago informacijo, kdo in kje je že katalogiziral rokopise določenega avtorja, bi popisovalci med seboj lahko tudi komunicirali in izvedeli še kaj več o določenem skladatelju in njegovih ohanjenih delih.

Ob računalniškem katalogiziranju se pojavlja tudi vprašanje, kako pri tem delu hitreje napredovati. Analiza zadnjih treh let (1999-2001) je pokazala, da je bilo katalogiziranju namenjenih v povprečju $43 \%$ celotnega delovnega časa enega katalogizatorja, kar pomeni približno dve popisani enoti na dan. ${ }^{4}$ Čas, ki je potreben, da na računalniških disketah shranjeni podatki tri do štirikrat letno potujejo $\mathrm{z}$ navadno pošto $\mathrm{v}$ pregled iz Ljubljane v Frankfurt in nazaj, obsega okoli $27 \%$ časa. V tem obdobju katalogiziranje ni možno in ga ponavadi porabimo za skeniranje. Po povratku disket iz Frankfurta sledijo korekture, ki so v preteklosti v povprečju zavzemale $10 \%$ vsega časa. ${ }^{5} \mathrm{Z}$ izrazom "ostalo delo" je definiran čas, porabljen za inštitutsko knjižnico, pripravljanje abstraktov za RILM in raziskovalno delo. Slednje med drugim vključuje tudi evidentiranje in inventariziranje glasbenih rokopisov, kar je že neposredno povezano z delom za RISM, nekakšna priprava gradiva za katalogiziranje. Opisano delo zavezema okoli $20 \%$ časa oziroma je naraslo od prvotnih $12 \%$ na $30 \%$ v zadnjem letu.

Prepričana sem, da so pretekle izkušnje pri katalogiziranju za RISM dobro izhodišče za nadaljnje delo. Na inštitutu bi radi našli način, kako število kataložnih zapisov, ki zdaj znašajo v povprečju 200 letno, še povečati. Morda bi prihranili nekaj časa, če bi pošiljali diskete v Frankfurt samo enkrat do dvakrat letno. Druga možnost pa se kaže v izkoriščanju notranjih rezerv v okviru inštituta oziroma v večji racionalizaciji delovnega procesa.

\footnotetext{
${ }^{4}$ Posamezni rokopisi, glede na zvrst in obseg, terjajo zelo različno porabo časa. Za maše in litanije s številnimi incipiti, je poraba časa večja kot na primer za vnose posameznih krajših del v okviru neke zbirke, ki jih lahko tudi kopiramo in na novo vnesemo oziroma popravimo samo spremenljive kategorije.

${ }^{5} \mathrm{~V}$ zadnjih dveh letih je bilo za korekture porabljenega samo 5\% časa, leta 1999, ko je bil opravljen tudi popis vodnih znamenj še za pretekla leta, so zavzemale $20 \%$ časa.
} 